\title{
Can you hear me here? Managing acoustic habitat in US waters
}

\author{
Leila T. Hatch ${ }^{1, *}$, Charles M. Wahle ${ }^{2}$, Jason Gedamke ${ }^{3}$, Jolie Harrison ${ }^{4}$, \\ Benjamin Laws ${ }^{4}$, Sue E. Moore ${ }^{5}$, John H. Stadler ${ }^{6}$, Sofie M. Van Parijs ${ }^{7}$ \\ ${ }^{1}$ Gerry E. Studds Stellwagen Bank National Marine Sanctuary, NOAA Office of National Marine Sanctuaries, \\ 175 Edward Foster Road, Scituate, MA 02066, USA \\ ${ }^{2}$ National Marine Protected Areas Center, NOAA Office of National Marine Sanctuaries, 99 Pacific Street, Suite 100-F, \\ Monterey, CA 93940, USA \\ ${ }^{3}$ Office of Science and Technology, NOAA Fisheries, 1315 East West Highway, Silver Spring, MD 20910, USA \\ ${ }^{4}$ Office of Protected Resources, NOAA Fisheries, 1315 East West Highway, Silver Spring, MD 20910, USA \\ ${ }^{5}$ Office of Science and Technology, NOAA Fisheries, 7600 Sand Point Way NE, Seattle, WA 98115, USA \\ ${ }^{6}$ Oregon-Washington Coastal Area Office, West Coast Region, NOAA Fisheries, 510 Desmond Dr SE, Lacey, WA 98503, USA \\ ${ }^{7}$ Northeast Fisheries Science Center, NOAA Fisheries, 166 Water Street, Woods Hole, MA 02543, USA
}

\begin{abstract}
Many marine animals have evolved over millions of years to rely on sound as a fundamental component of their habitat. Over the last century, increasing noise from human activities has significantly affected the quality of underwater acoustic habitats. These changes can lead to reduced ability to detect and interpret environmental cues used to perform critical life functions (e.g. select mates, find food, maintain group structure and relationships, avoid predators, navigate). The National Oceanic and Atmospheric Administration (NOAA), as the US federal agency with primary responsibility for protecting marine animals and their habitats, is developing an agency-wide strategy that emphasizes the ocean spaces that these animals need, and the importance of acoustic conditions in those places. This strategy seeks to reach beyond initial goals of reducing acute impacts due to noise (protecting hearing and reducing physical harm) to better account for the importance of underwater sound in marine ecosystems. This paper outlines science needs associated with acoustic habitat characterization and the assessment of noise impacts on habitats, which provide information critical to NOAA's prioritization of future place-based research and management. NOAA's spatial management tools are examined relative to acoustic habitat protection goals, which seek to match the ecological scales over which noise is impacting marine wildlife, including endangered species. Recommended actions are identified to address these broad spatial and long temporal scales, including international work on quieting technologies, registries of accumulated noisy events, and an enhanced role for NOAA's National Marine Sanctuaries in science, management, and outreach associated with acoustic habitat protection.
\end{abstract}

KEY WORDS: Habitat $\cdot$ Marine $\cdot$ Acoustic $\cdot$ Protected areas $\cdot$ Soundscape

\section{INTRODUCTION}

The US National Oceanic and Atmospheric Administration (NOAA) is a steward of the nation's oceans, with a variety of statutory mandates for conservation and management of coastal and marine ecosystems

${ }^{*}$ Corresponding author: leila.hatch@noaa.gov and resources of ecological, economic, and cultural significance. To this end, NOAA is charged with protecting the long-term health of a wide variety of aquatic animal populations and the habitats that support them, including whales, dolphins, turtles, fishes, and invertebrates. While these animals fill very dif-

Outside the USA @ the Government of the United States 2016. Open Access under Creative Commons by Attribution Licence. Use, distribution and reproduction are unrestricted. Authors and original publication must be credited. 
ferent roles in marine ecosystems, many of them share a common and fundamental biological need: the ability to hear, produce, and respond to sound.

The purposeful use of sound for communication by marine mammals, many fish, and a few marine invertebrates is well documented (reviewed by Tyack \& Clark 2000, Normandeau Associates 2012, Ladich 2015). For example, fin and blue whales produce lowfrequency calls that are thought to play roles in finding mates, sharing food resource information, and navigating at ocean-basin scales (Payne \& Webb 1971, Morano et al. 2012). In contrast, bottlenose dolphins use higher-frequency signals to maintain social structure, identify individuals, and echolocate during foraging (Janik \& Slater 1998). Fish are well known to produce loud low-frequency choruses for communicating with conspecifics and attracting mates (Myrberg 1981). Cavitating bubbles produced by snapping shrimp emit sound upon their collapse that stun prey and provide a means for individuals to communicate with one another and defend territories (Versluis et al. 2000). In addition, there is evidence from both terrestrial and marine organisms illustrating the ecological importance of adventitious sounds: those gathered opportunistically from the surrounding habitat through eavesdropping rather than from a purposeful sender (Barber et al. 2010, Slabbekoorn et al. 2010, Radford et al. 2014).

Many animals hear and respond to frequencies outside of those they produce, underscoring the importance of eavesdropping on other species or of detecting meaningful sounds made by the physical environment. Aquatic examples are wide ranging, including baleen whales responding to sounds within frequencies used by killer whales (e.g. Goldbogen et al. 2013); herring detecting sounds used by echolocating whales; fish and crab larvae using reef sounds dominated by snapping shrimp as directional cues; sharks approaching the sounds made by struggling prey; and surface-feeding fish responding to sounds of prey falling into the water (reviewed by Slabbekoorn et al. 2010). Barber et al. (2010, p. 183) summarize a pattern that appears broadly consistent for both terrestrial and marine realms:
It is clear that the acoustical environment is not a collection of private conversations between signaler and receiver but an interconnected landscape of information network and adventitious sounds.

These complex and dynamic assemblages of natural sounds are inherent aspects of marine habitats (Fig. 1). All of the sound present in a particular location and time, considered as a whole, comprises a 'soundscape' (Pijanowski et al. 2011). When examined from the perspective of the animals experiencing it, a soundscape may also be referred to as 'acoustic habitat' (Clark et al. 2009, Moore et al. 2012a, Merchant et al. 2015).

Acoustic habitats identified today are often significantly modified by noise produced by human activities, and thus efforts must be made to characterize both their natural and altered conditions. Such activities, and the resulting noise levels that they produce, are increasing throughout coastal and ocean waters

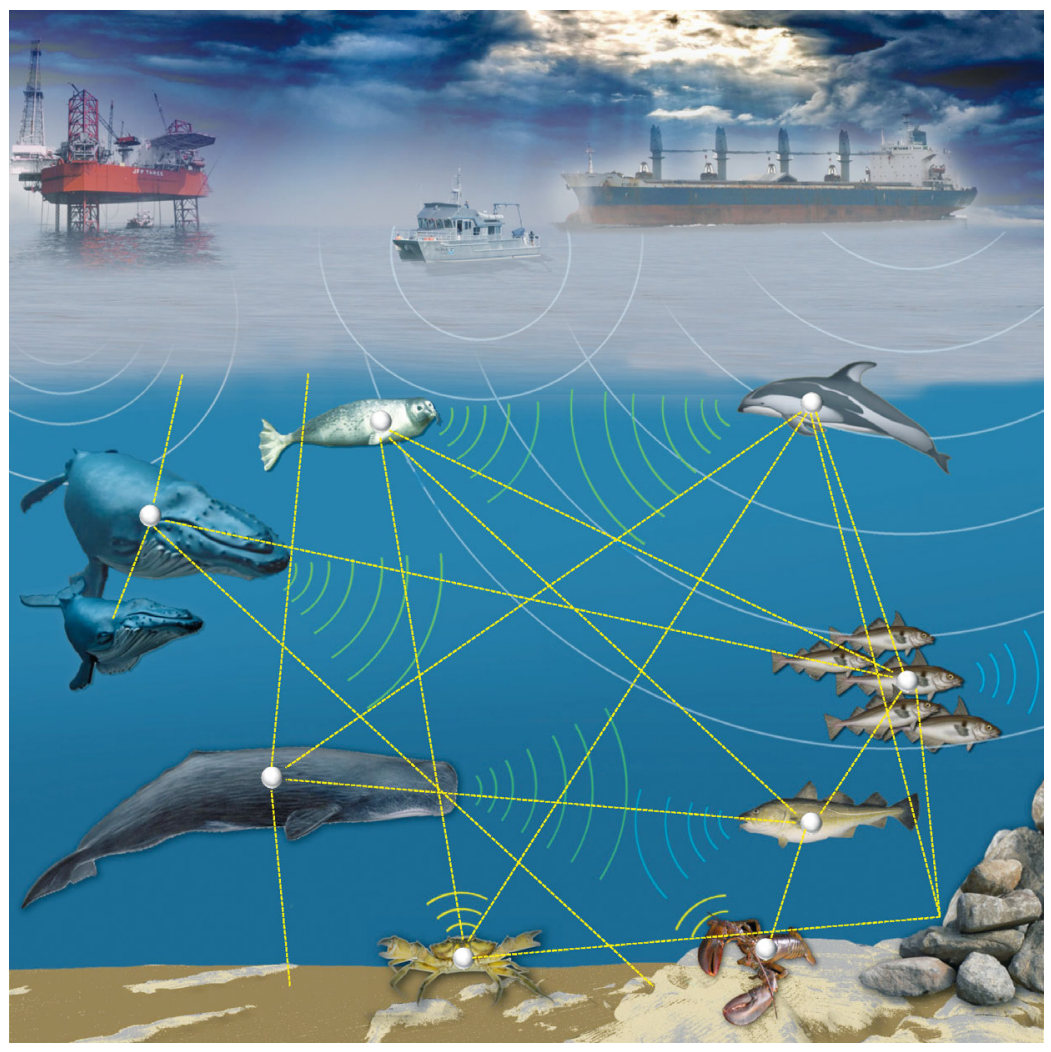

Fig. 1. Potential acoustically mediated information pathways (yellow dotted lines) in a marine community, including, but not limited to, purposeful communication between individuals, use of echolocation over distances (large and small), eavesdropping on sounds made by other animals, detection of human activities, and identification of seafloor characteristics, all supporting biologically important behaviors such as settlement, recruitment, feeding, migration, and reproduction. White circles and blue, green and yellow semicircles generically represent information-gathering opportunities and sound production, respectively 
in both time and distribution. There are few aquatic areas where anthropogenic noise is absent. Changes in noise conditions over time are predicted to vary considerably among ocean and coastal areas. In some heavily used areas, several-fold increases in the contribution of human noise to acoustic habitats have been measured over just a few decades (Andrew et al. 2002, McDonald et al. 2006). While some marine animals are capable of adjusting communication signals in the presence of noise (e.g. Holt et al. 2009, Parks et al. 2010), it is unknown whether these changes can transfer between generations or whether they result in long-term fitness consequences. Relative to the life spans of marine organisms, noise levels have seen significant growth over just a handful (e.g. some fish, turtles and marine mammals) to tens (e.g. some fish and invertebrates) of generations. Given this rapid increase, the potential for true evolutionary adaptation to a noisier environment is limited.

NOAA recognizes the need to develop an approach to underwater noise management that considers not only its effects on individual animals, but also the importance of natural sounds in the places where those animals live. As the world's coasts and oceans become busier and noisier, NOAA will be challenged to craft and implement new management approaches that balance the competing needs of coastal and ocean resource users and natural acoustic habitats. In this paper, we describe key elements of an agencywide strategy to more comprehensively manage noise impacts on acoustic habitats, including implications for the science needed to assess habitat status and noise influences. We then examine NOAA's management tools and consider their application to acoustic habitat protection goals, highlighting activities that are underway or could be undertaken to achieve these goals.

\section{BROADENING NOAA'S NOISE MANAGEMENT APPROACH}

\section{Describing acoustic habitats}

The place where an animal lives is called its 'habitat' and is described by its physical and biological attributes, including its acoustic conditions. Under strict habitat definitions, acoustic habitat is an attribute of the area surrounding individual animals; however, the concept is commonly expanded to refer to habitat as the place where multiple species occur together under similar environmental conditions. A habitat can therefore be distinguished from surrounding habitats on the basis of both its species composition and its physical environmental characteristics (e.g. type of seabed, tidal currents, salinity). An acoustic habitat can similarly be attributed to an assemblage of species that are known to collectively experience and often contribute to a natural soundscape that is distinguishable from surrounding soundscapes. Soundscape measurements can be associated with aquatic habitats that have been classified using more traditional data types (e.g. McWilliam \& Hawkins 2013, Lillis et al. 2014). Such measurements can illustrate variance in space, time, and frequency content, depending on what species are present at the time of measurement. For example, natural acoustic habitats within tropical reef areas may be heavily dominated by the popping of snapping shrimp and will therefore differ dramatically from those within temperate boulder fields inhabited by the grunting and thrumming of fish such as cusk, sculpin, and cod (e.g. Rountree et al. 2006, Staaterman et al. 2013). Acoustic habitats may vary seasonally in association with the presence of animals that produce sounds, whether they are feeding, reproducing, or simply migrating through the area (e.g. Moore et al. 2012b, Parks et al. 2014). Environmental sources of sound can also show strong temporal trends, such as louder, stormier winter months and quieter, lower-wind summer months, contributing to large intra-annual differences in natural acoustic habitats (Wenz 1962, Urick 1983). Such natural sources of variance must be accounted for in further evaluating alterations of such habitats by noise from human activities.

Although a few noise sources produce relatively consistent acoustic input to habitats (e.g. large commercial shipping), the cumulative footprint of noise from human activities is often dynamic. Noise made by human activities varies widely in its frequency content, duration, and loudness. Consequently, anthropogenic noise can affect acoustic habitats locally for brief periods of time as well as chronically over large areas for long durations. The characteristics of noise sources greatly influence the types of impacts they may have on marine animals and their acoustic habitats. At close proximity, loud noises can result in hearing damage and other physical injury to, or even death of, animals. Sudden, erratic, or acute noises can additionally be perceived as threats, leading to adverse responses, while frequent and chronic noise can interrupt communication and disrupt the ability to detect acoustic cues. All of these types of impacts can have viability consequences (see Fig. 3 in Francis \& Barber 2013). 
Studies of fishes have quantified the negative impacts of noise-disrupted behavioral patterns on foraging success (Purser \& Radford 2011) and predator awareness (Voellmy et al. 2014, Simpson et al. 2015). Effects of lost listening opportunities in noisy conditions can be assessed for specific, identified environmental, or adventitious cues of importance, or more generally based on reduction in the volume of space available for acoustic detection (see Box 2 in Barber et al. 2010). Time-series data documenting changes in noise conditions are not typically available. Estimates of change in the status of acoustic habitats can incorporate contemporary noise measurements and predictive modeling with and without noise sources, or historical measurements made in areas with similar oceanographic parameters (e.g. Hatch et al. 2012). More recently, the US National Park Service has been developing modeling techniques to predict levels of noise under different conditions for large areas of the continental USA, with one purpose being to gauge progress towards park soundscape management goals (Mennitt et al. 2014).

\section{NOAA's tools for acoustic habitat risk assessment}

The need to develop long-term recording assets in US waters to enable full characterization of localized acoustic habitats, and support standardized comparisons both within habitats over time and among habitats of potential management interest, is well recognized both by NOAA and other federal agencies (Southall et al. 2009). Some places, such as Stellwagen Bank National Marine Sanctuary and the northeast region in general, have developed longer-term and higher-resolution monitoring efforts as a result of established collaborations between NOAA scientists and non-federal partners, relying on substantial funding from other federal agencies (Van Parijs et al. 2015b). Longer-term recordings have also been funded by non-NOAA federal agencies associated with monitoring the impacts of established noiseproducing activities in acoustic habitats of interest to NOAA (e.g. off southern California and North Carolina associated with military training ranges and in the Alaskan Arctic associated with oil and gas exploration and extraction). NOAA is working with these partners to ensure that such data assets can support assessments of both baseline conditions of acoustic habitats and changes in their status through time. Despite efforts to improve and increase standardized passive acoustic data collection, NOAA cannot listen to all the places in its management charge all the time. Sound-field modeling provides opportunities to characterize acoustic habitat conditions in places with no or limited measurements, and to explore the predicted consequences associated with changes in the types, distributions and densities of noiseproducing activities over time. NOAA has invested in the development of such modeling approaches within US waters at various resolutions and scales (http://cetsound.noaa.gov/sound_data; Fig. 2).

As NOAA looks to integrate acoustic habitat protection within its science and management activities, it is helpful to examine which tools developed to support the agency's traditional, species-based noise impact evaluation processes can be leveraged to inform broader evaluation of impacts on acoustic habitats. Noise impact assessments, whether addressing direct effects to individual animals or degraded acoustic habitat, share basic science needs. Chief among them are to identify: (1) which species use or make sound (including hearing, sound production, and sensitivity); (2) the role of sound in their life histories (acoustic ecology and behavior); and (3) how they use their environments (including their distribution and habitats that support biologically important activities, such as reproduction and feeding). However, NOAA's historical focus on tissue damage and behavioral responses has underemphasized additional science needs that would inform understanding of the consequences of anthropogenically altered acoustic habitats. For example, more science is needed to characterize variation in the production or perception of intraspecific communication signals in natural areas with different background noise conditions. Likewise, more science is needed to better document the quietest signals that

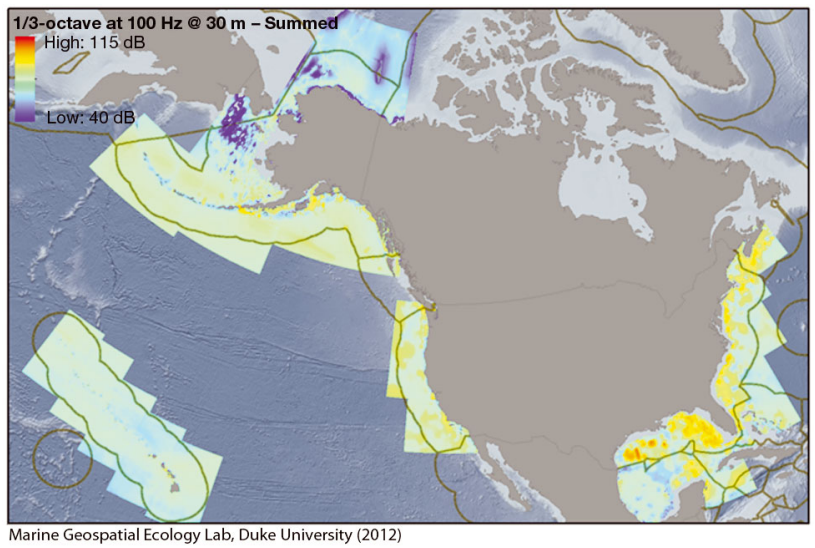

Fig. 2. Predicted low-frequency (one-third octave centered at $100 \mathrm{~Hz}$ ) average annual noise levels (equivalent, unweighted sound pressure level in decibels re $1 \mu \mathrm{Pa}$ ) at $30 \mathrm{~m}$ depth, summing contributions from a variety of human activities (see http://cetsound.noaa.gov/sound_data) within the US Exclusive Economic Zone (brown lines) 
animals can (and do) perceive in the wild. Recent investments in the development of models to interpret the consequences of behavioral responses to noise (e.g. Population Consequences of Disturbance, SMRU Consulting 2015) have the potential to, but have yet to, address the long-term effects on the viability of populations when individuals are less able to hear conspecifics, prey, predators, or key environmental awareness cues. There is a clear need to ensure that such modeling can address data-poor as well as datarich management contexts. Tools that are being adapted to implement ecosystem-based management of fisheries (e.g. productivity-susceptibility analyses; Food and Agriculture Organization of the United Nations 2015) allow for rapid risk assessment when faced with uncertainty regarding ecological relationships as well as population demographics. Such techniques could generate estimates of risk for individual populations and ecosystems due to noise-altered habitat or displacement from habitat due to noise, and could integrate risk associated with multiple threat types.

Place-based risk assessments are a particularly useful framework for integrating multiple data resources in order to inform agency decision-making. Characterizations of the co-occurrence of high-value target species, high-value target places, and predicted and measured noise levels can inform agency actions at several scales (Erbe et al. 2014). In some cases, current passive acoustic monitoring and noise modeling capacity may be sufficient to support NOAA's assigning high risk to a high-value acoustic habitat that is currently quiet when compared to other areas, and where action is necessary to maintain lower noise levels. In other cases, high risk may be associated with a high-value habitat that is currently relatively loud and where action is necessary to reduce noise levels. Given the status of standardized long-term passive acoustic monitoring and noise modeling capacity in US waters today, however, available data may or may not be sufficient to support mitigation design (i.e. identification of dominant noise contributions at various spatial, temporal, and spectral scales). NOAA's actions to strengthen protection for high-risk acoustic habitats will therefore need to be adaptive, continually improving both the design and implementation of effective mitigation.

\section{NOAA's tools for managing acoustic habitat}

Historically, NOAA has managed the impacts of noise on its trust resources by using legal frameworks designed to protect target populations and species.
These populations and species are those that society has determined need special care, including those that are endangered or threatened, and those that are of particular ecological, cultural, or economic interest, including all marine mammals. The Endangered Species Act (ESA 1973) and the Marine Mammal Protection Act (MMPA 1972) are the primary statutes by which NOAA requires mitigation strategies and monitoring action designed to reduce or eliminate and better understand the impacts that specific types of noise have on this limited suite of species. Under these statutes, management action has focused on reducing the potential for relatively loud noise sources (e.g. airguns, sonars, pile drivers) to unambiguously injure animals or cause them to respond behaviorally over (usually) relatively small spatial and temporal scales. This traditional approach has played an important role in fulfilling NOAA's stewardship mandates by preventing or minimizing acute harm to individual animals.

The US National Ocean Policy (US NOP; Executive Order 13547 2010), however, firmly directs federal agencies to implement ecosystem-based approaches to management. Fundamentally place-based, these management efforts seek to conserve functioning ecosystems and the services they provide. Ecosystembased management approaches highlight the importance of natural habitats and parallel additional efforts within NOAA to focus the agency's many mandates to protect and restore habitats. Inherent in these policy directives is the need for NOAA to begin to address the widespread degradation of natural acoustic habitat for a broad range of acoustically sensitive species due to increasing noise from accumulated anthropogenic sources.

The degree to which NOAA's management tools can be used to focus on specific habitats ranges widely. Many, but not all, areas managed or co-managed by NOAA meet the national definition of a marine protected area (MPA). In the US, an MPA is broadly defined as

an area of the marine environment that has been reserved by federal, state, territorial, tribal, or local laws or regulations to provide lasting protection for part or all of the natural and cultural resources therein (Executive Order 13158 2000, Section 2(a)).

Covering over half the total area of the US's Exclusive Economic Zone (EEZ) and occupying most habitat types (Table 1), US MPAs have been established by a variety of federal, state, and tribal agencies to protect a diversity of species (e.g. mammals, fish, invertebrates, and plants), cultural resources, and natural ecosystem features and processes. MPAs in the 
Table 1. Prevalence and diversity of management approaches for all existing Marine Protected Areas (MPAs) in US Exclusive Economic Zone (EEZ) waters, as well as National Oceanographic and Atmospheric Administration (NOAA)managed or co-managed areas

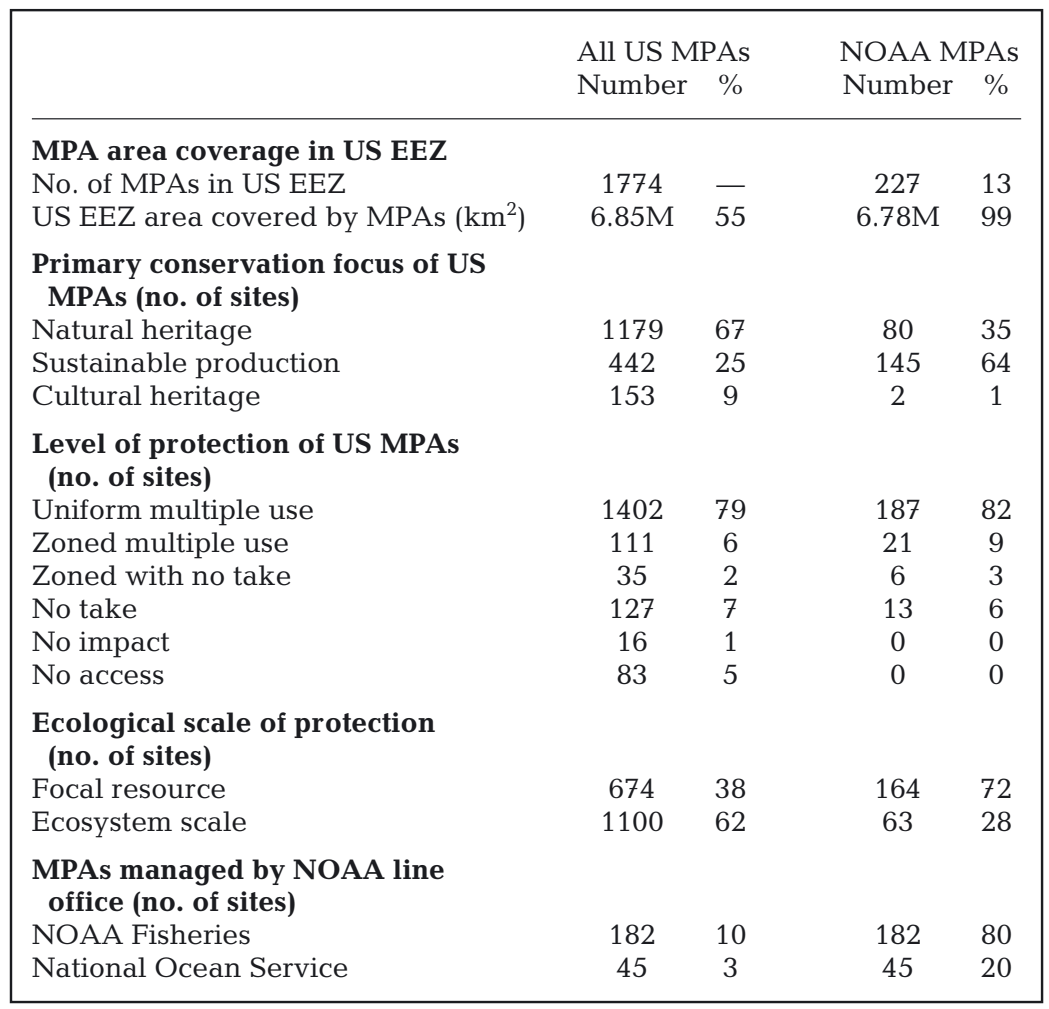

USA also vary widely in their conservation purposes, and in the associated level, scale, and permanence of protection afforded the resources they protect (Table 1, categories discussed in National Marine Protected Areas Center 2011). NOAA manages or co-manages only $13 \%$ of MPAs within US waters. However, these $13 \%$ represent $99 \%$ of the total area contained within US MPAs. This is due mainly to the existence of many large sustainable production fishery MPAs, a few large marine mammal MPAs on the east coast, and 4 large National Marine Monuments in the Pacific. While two-thirds of US MPAs have a broad ecosystems conservation focus, two-thirds of NOAA MPAs focus on the conservation of specific focal resources. The remaining one-third of NOAA MPAs, including 15 sites managed by the Office of National Marine Sanctuaries, focus on comprehensively protecting marine ecosystems. Regardless, as the main federal managers of large, offshore MPAs, NOAA plays a key role in shaping and executing US marine spatial protection.

A fuller understanding of how and where NOAA's existing spatial management tools can be used to sustain viable acoustic habitats will help the agency meet and adapt to the growing threat ocean noise poses to our trust resources. NOAA's place-based tools can generally be categorized as those that are applied by the agency to fulfill mandates to protect specific, high-value populations or species, versus those that are applied towards protecting a high-value area, including all its attributes (Table 2). Here, we use the term 'high value' to generalize the many statute-specific definitions that are used to identify the specific populations, species, and areas that NOAA is mandated to protect (e.g. endangered or commercially important). The tools listed here include only those with links to NOAA's statutory authorities or actions. Marine National Monuments, for example, are not de facto included in this table, as their designation under the Antiquities Act (1906) is an act of the President not the Agency, and does not, in and of itself, provide NOAA with additional statutory authorities to support management goals. That said, the NOAA National Marine Fisheries Service's Marine National Monument Program serves to coordinate the development of management plans, scientific exploration and research programs under their existing authorities (e.g. MMPA, ESA, and Magnuson-Stevens Fishery Conservation and Management Act, MSFCMA 1996) within all 4 of the Marine National Monuments in the Pacific Islands Region. In addition, NOAA's Office of National Marine Sanctuaries, with authorities under the National Marine Sanctuaries Act (NMSA 1992), has active management roles within 2 Marine National Monuments, Papahanaumokuakea and Rose Atoll.

The tools listed are not exhaustive of NOAA's authorities, but provide examples of different types of measures within the agency's jurisdiction that are currently or could in the future be applied to address noise impacts on acoustic habitat. Some authorities have operational areas that can authorize NOAA actions over very large areas, encompassing the full geographic range of target populations, species, or their habitats. Cetacean Biologically Important Areas were identified for certain cetacean species through NOAA's CetMap program (Van Parijs et al. 2015a), and are included here despite their lack of statutory authority due to NOAA's role in supporting their de- 


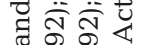

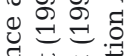

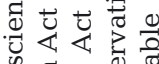

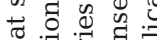
要

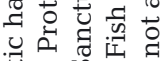

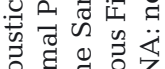
of

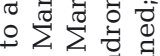

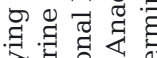

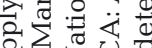

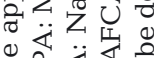

a

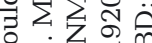

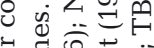

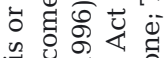

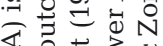

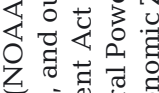

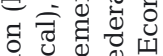
50.

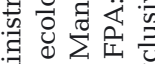

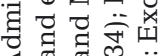
항

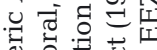
을

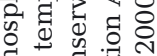

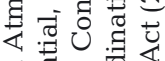

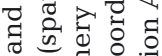

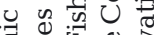

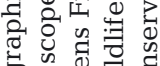

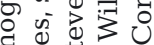
喝

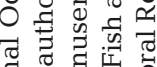
링 部品

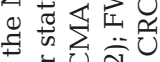

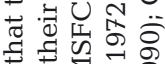
wo 2 일 等 啰 웡

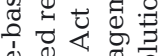

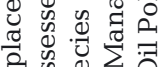
o ตั

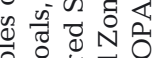

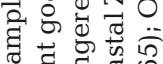

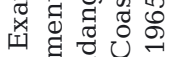
ن

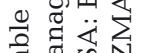

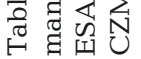

\begin{tabular}{|c|c|c|c|c|c|c|c|c|c|c|}
\hline 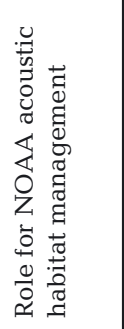 & \multicolumn{3}{|c|}{ 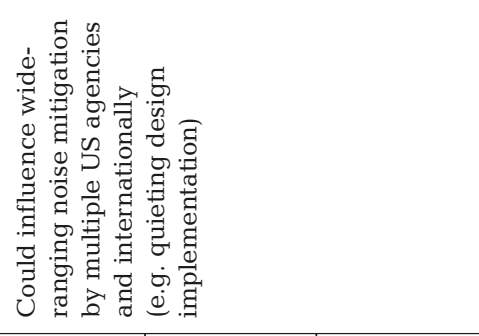 } & 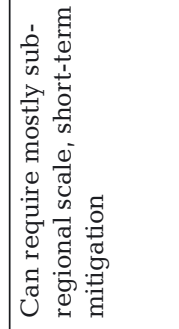 & 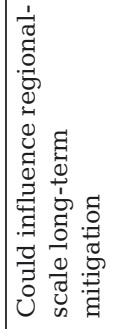 & 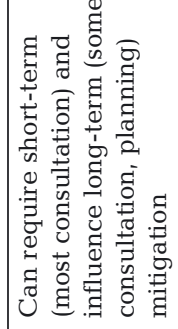 & 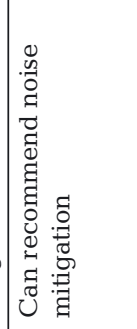 & 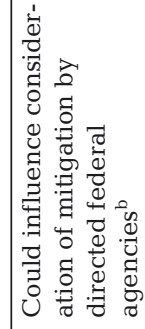 & 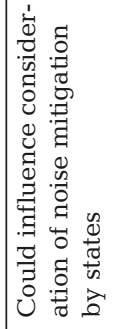 & 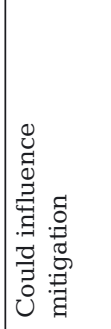 \\
\hline 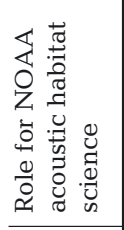 & 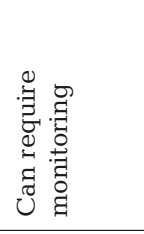 & 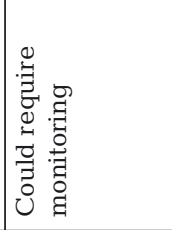 & 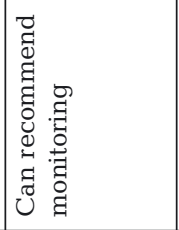 & 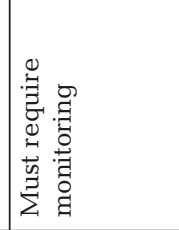 & 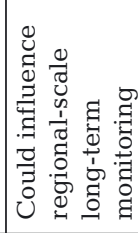 & 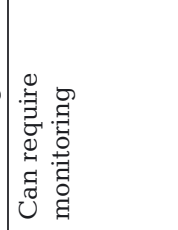 & 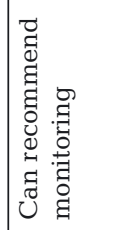 & 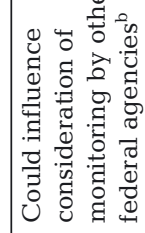 & 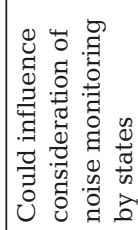 & 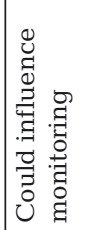 \\
\hline 它 & ż & z̊n & $\stackrel{\circ}{z}$ & ż & ż & z & z & z & Z & $\stackrel{\circ}{z}$ \\
\hline 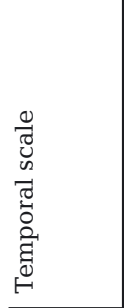 & 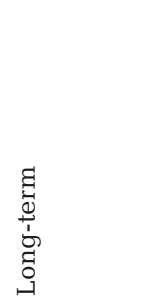 & 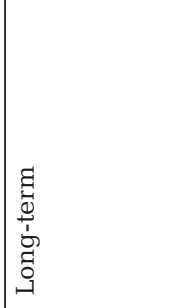 & 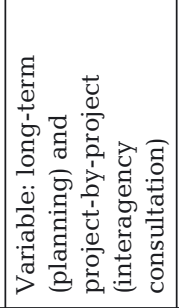 & 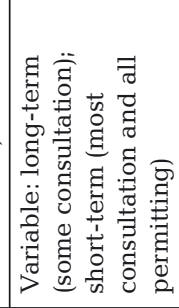 & مि & 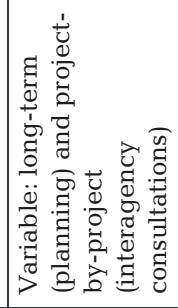 & 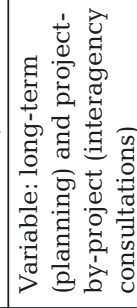 & 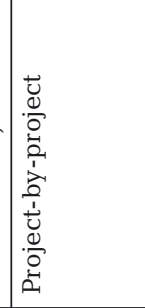 & 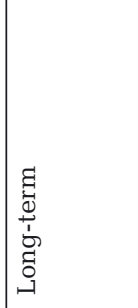 & 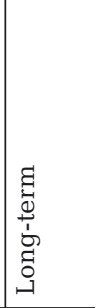 \\
\hline 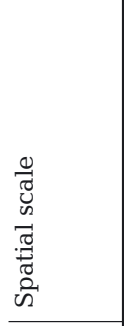 & 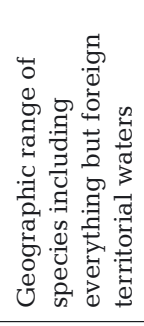 & 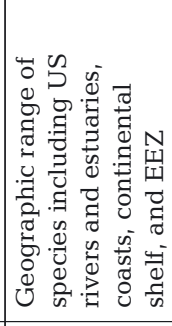 & 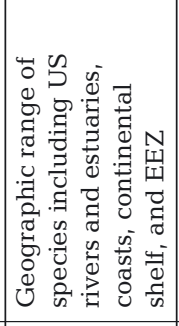 & 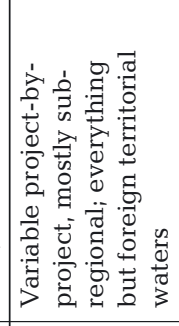 & 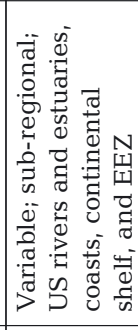 & 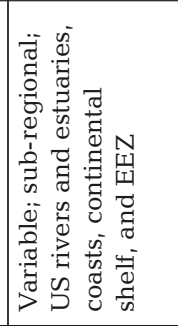 & 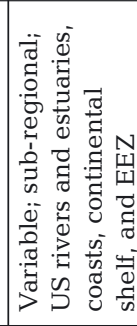 & 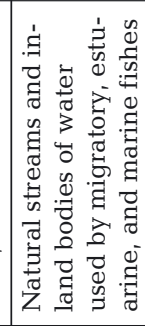 & 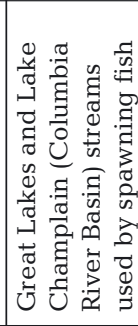 & 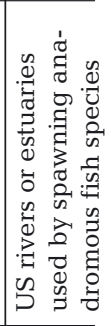 \\
\hline 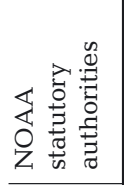 & 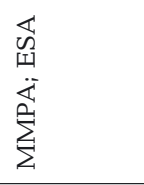 & 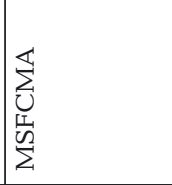 & 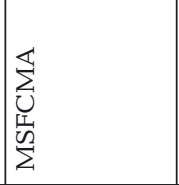 & 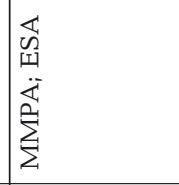 & 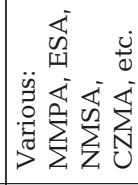 & 死 & 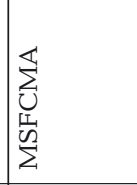 & 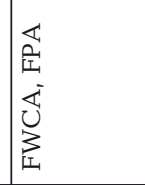 & 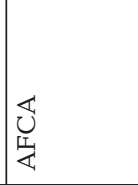 & 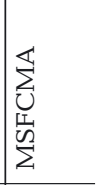 \\
\hline 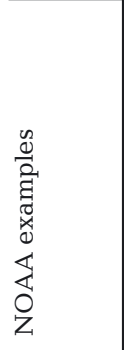 & 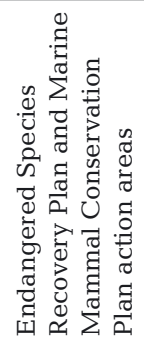 & 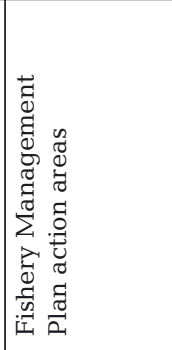 & 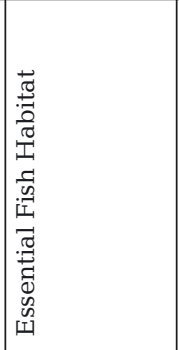 & 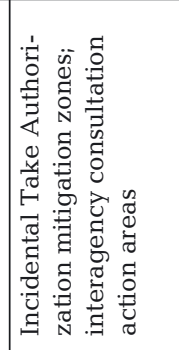 & 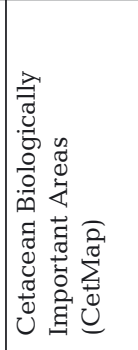 & 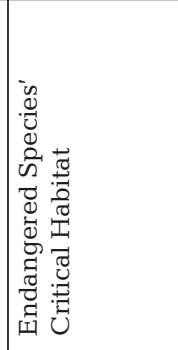 & 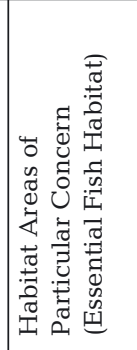 & 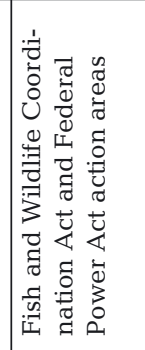 & 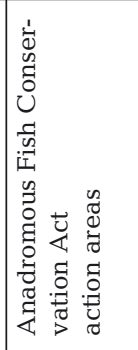 & 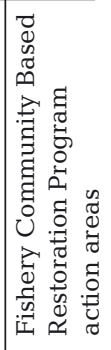 \\
\hline 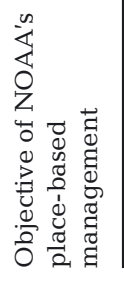 & 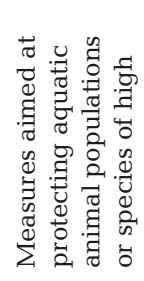 & & & & & & & & & \\
\hline
\end{tabular}




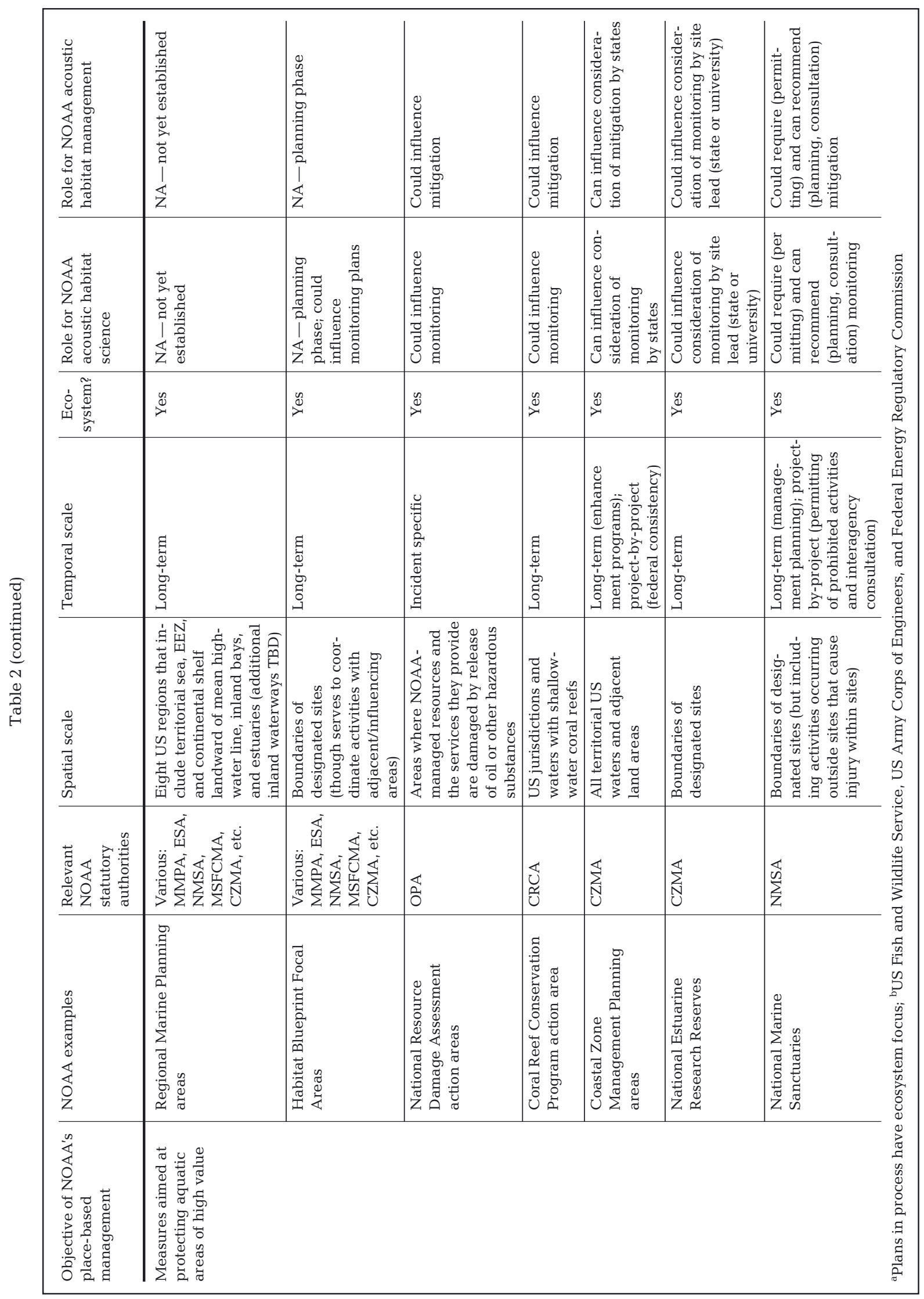


velopment and their direct link to NOAA's noise impact assessment activities. Similarly, several new tools that support increasing attention by the agency to ecosystem-based management are listed in the table. Although many are in early stages of development and are not accompanied by new statutory authorities, they represent promising new mechanisms for focusing agency attention towards restoration or enhanced protection of high-value aquatic places (e.g. Habitat Blueprint Focal Areas, NOAA Fisheries 2015a; Important Ecological Areas, Northeast Regional Planning Body 2015). Finally, several tools that authorize NOAA to provide technical expertise to other state or federal decision-making processes are listed, due to the roles that such influence could play in broadening the scope of NOAA's direct actions.

Scales of applicability (spatial, temporal, and ecological) are considered for each tool, in order to examine their limitations and strengths for addressing acoustic habitat management goals. Potential noise management outcomes are classified generally as influencing either mitigation or monitoring of noise exposure for target taxa or areas. Mitigation includes actions taken to reduce the occurrence of noise impacts. Here, monitoring specifically addresses measurements taken during noise-producing activities (required of those promoting the activity) in order to evaluate potential for impact that may or may not occur, and the information gained can inform future management decisions. In addition, NOAA has a variety of statutory mandates that support the agency's own need to monitor noise impacts on the populations, species, and areas it manages. Those measures are not listed here, nor are more general National Environmental Policy Act (NEPA 1969) mandates that direct all federal agencies to evaluate environmental impacts of proposed activities, including noise impacts, to trust resources. These self-directed mandates can be used to strengthen the agency's actions towards acoustic habitat management priorities.

\section{THE PATH FORWARD}

NOAA has embarked on a path to better understand the importance of sound in marine ecosystems, and to more effectively manage anthropogenic threats to acoustic habitats using both current and augmented tools. Growing threats from noise to acoustically sensitive species coupled with limited agency resources needed to address these challenges, suggest a need to simultaneously move forward aggressively while making clear strategic decisions about where and how to prioritize those efforts in the coming years. While specific decisions in the future will be influenced by many factors, the following actions seek to match the broad spatial and long temporal ecological scales over which noise is impacting acoustic habitats.

\section{Create and support international initiatives to reduce influence from distant noise sources}

NOAA acknowledges that addressing chronic noise conditions within some acoustic habitats of concern will necessitate management action that can reduce noise exposure over very large spatial scales (McCarthy 2004, Hatch \& Fristrup 2009). Drivers for wideranging mitigation solutions stem from both presumed species-specific communication ranges (e.g. fin and blue whales) and documented propagation distances for low-frequency noise sources (e.g. seismic airguns and ships). Distant sources of noise will have differential impacts within acoustic habitats of interest. In general, deep-water habitats at northern hemisphere mid-latitudes or in highly trafficked seas are likely to be significantly influenced by wide-ranging noise sources (National Research Council of the US National Academies 2003). Additionally, many highly migratory populations of endangered baleen whales are known to produce low-frequency calls and songs throughout most of their ranges (e.g. Charif et al. 2001, Oleson et al. 2014). Acoustic conditions could be considered relevant to these species wherever they occur. NOAA's authorities for addressing range-wide threats to target populations and listed species often explicitly recognize and direct multilateral approaches (e.g. endangered species recovery planning). Such drivers provide important mechanisms for the agency to engage in long-term, international efforts to reduce chronic noise influence, in addition to more nationally focused activities.

Efforts to recover, restore, and ensure sustainable harvest of species over large ranges identify key partnerships with other agencies and countries, and industries, with direct mechanisms to influence implementation of quieting programs. NOAA has provided such leadership in efforts to develop technical guidelines to reduce noise from commercial ships through the United Nations' International Maritime Organization. In partnership with the US Coast Guard, NOAA supported the US's chairing of these efforts beginning in 2008, with successful passage of guidelines in 2014 (International Maritime Organization 2014). NOAA continues to work with interagency and non-governmental partners to support 
international implementation of these guidelines. Key next steps include pilot programs for select shipping companies and, ideally, select ports, with interests in supporting 'green ship' development, in which new ships are built or existing ships are modified to include quieting in design and operational goals. Pilot programs would evaluate time horizons for cost recovery (e.g. via increased fuel efficiency, reduced maintenance), consider integration of quieting goals with other environmental protection goals included in green ship design projects, and develop monitoring and docking incentives associated with participating ports.

NOAA has been less directly engaged in international efforts to encourage the development of quieter technologies to modify or replace other dominant low-frequency noise sources, like airguns, other seismic sources, pile-driving activities, and vessel dynamic positioning systems that are used in a wide variety of offshore energy development phases (e.g. exploration, platform construction, extraction/ generation). For such sources, NOAA's current regulation and consultation activity to address physical and behavioral effects due to acute noise exposure focuses on noise-reduction techniques to reduce peak pressures or short-term (e.g. $1 \mathrm{~d}$ ) accumulated energy experienced by animals swimming nearby (e.g. some pile-driving sound-attenuation techniques). Broadening such designs to address lost listening opportunities over larger spatial and longer temporal scales will necessitate setting of engineering targets that reference biological effects at those scales. Longer-term effect targets are emerging from modeling the population-level consequences of displacing harbor porpoises from their habitat in the North Sea as a result of regional wind farm development (SMRU Consulting 2015). However, effect targets assessed via modeling of consequences mediated through full ecosystems are also important, to ensure that species-specific noise optimizations benefit habitat conditions more holistically. Many of the companies conducting noise-producing activities in support of offshore energy exploration and production have increased their investment in quieting technologies, recognizing that quieter alternatives would be environmentally preferable and would reduce the complexity of operating within highly variable international regulatory constraints. For example, a wide range of international oil companies and the International Association of Geophysical Contractors continue to invest in the development of marine vibroseis technology as an alternative to airgun technology for use in seismic data acquisition (E\&P Sound \&
Marine Life Joint Industry Programme: www.sound andmarinelife.org).

\section{Improve and apply national tools to reduce cumulative impacts}

Given the increasing number of noise producers seeking permits from NOAA to authorize impacts, there is a need to address the implications of accumulated exposure to acoustic habitats. This need is not isolated to noise among environmental stressors, nor to the USA alone. Tools to address cumulative, multi-source effects over wider spatial scales are emerging in the European Union associated with the implementation of the Marine Strategy Framework Directive (EU MSFD). The EU MSFD defines its objective, Good Environmental Status, to include the requirement that 'Introduction of energy (including underwater noise) does not adversely affect the ecosystem' (EU MSFD 2008). Regional registries of noise-producing events, developed by individual countries (e.g. UK and The Netherlands) but with high levels of multi-lateral collaboration, are being used to characterize contributions to national and regional noise budgets. Importantly, these registries collect information regarding nationally permitted noisy activities both at the times they are proposed and then again after they are completed. Such registries thus allow European countries with collective, regional interest in regulating noise to describe relative, actualized noise contributions to localized acoustic habitats of concern. Noise predictions based on registered events can be compared to monitoring data to estimate remaining contributions from nonregistered source types.

A geospatially explicit registry of all federally authorized (i.e. NOAA permitted and/or requiring nonNOAA federal action) noise-producing events in US waters would inform many facets of NOAA's activities to address cumulative noise impacts on high-risk acoustic habitats. In parallel with EU MSFD efforts, such a registry would inform NOAA's role in implementing the US National Ocean Policy. The US National Ocean Policy encourages Regional Marine Planning as

a science-based tool that regions can use to address specific ocean management challenges and advance their economic development and conservation objectives (National Ocean Council 2013a, p. 21).

Regional Marine Planning Bodies have been established in several US regions, with the northeast and mid-Atlantic regions the furthest advanced towards 
finalization of Regional Marine Plans. Several Regional Planning Bodies (as well as similar regional collaboratives) have invested in mapping coastal and offshore human use patterns as critical information to inform discussions of compatibility among uses and to achieve ecosystem protection goals. Some noiseproducing activities are likely well captured by current mapping initiatives, including the likely influence of ocean-going (e.g. cargo, tanker) and some more localized commercial (e.g. fishing, ferries, tugtow) and recreational (e.g. fishing, pleasure) vessels on regional acoustic habitats (e.g. SoundMap, http:// cetsound.noaa.gov/sound_data). Others are captured in more generalized and often low-resolution projected terms, including levels of expected activity within boundaries of lease blocks for energy development or ranges for military activities. Higher-resolution information describing actualized activity levels evaluated after they occurred would significantly improve place-based characterization of noise contributions in areas with high federal authorization activity.

In other areas, improving noise estimates will demand approaches that account for activity types that are not federally authorized. In particular, noise in nearshore waters can be influenced by a diversity of human activities that may or may not require local, state, tribal, or federal authorizations, including offshore communication and energy installations, port and harbor operations, maintenance of bridges and waterways, pleasure craft, and even onshore road traffic. Inshore areas are often of high concern for environmental management (Table 2), as they support biologically important (and often acoustically sensitive) reproductive and early life stage behaviors for a wide range of aquatic taxa, including invertebrates, fish, and mammals. Measurements of coastal noise levels are increasingly collected by nearshore monitoring efforts, although they disproportionately sample locations and time periods that contain noisy events and are often not regionally centralized. A new land-based modeling technique would, however, leverage the increasing quantity and spatial coverage of coastal noise measurement data and shows great promise for improving the accuracy and accessibility of noise predictions over large scales. This technique has been applied to relate well-distributed noise measurement data to geospatial datasets that describe key anthropogenic, biological, and geophysical predictors of noise, generating maps of noise levels that span the US continental states (Mennitt et al. 2014, www.nature.nps. gov/sound/soundmap.cfm). Although necessitating continual improvements in noise measurement databases, this technique reduces reliance on high-resolution descriptions of noisy activities. Such regional to coast-wide noise predictions would improve representations of cumulative conditions within both Coastal Zone Management and Regional Marine Plans. States with approved Coastal Zone Management Plans can then determine whether federal actions or permits associated with proposed activities are consistent with the enforceable policies of their plans (Coastal Zone Management Act 1972, see Table 2). While Regional Marine Plans may not explicitly seek to reduce accumulated noise impacts within high-risk acoustic habitats, such an outcome is inherent to planning objectives that seek to reduce regulatory burdens for both NOAA and those promoting noise-producing activities by improving information regarding place-based cross-sectoral and environmental compatibility (National Ocean Council 2013b).

Marine planning seeks to augment statutorily directed consultation and environmental impact assessment processes that are standardly used to address noise impacts (Table 2). Registries of federally permitted noise-producing events would allow NOAA, in concert with long-term monitoring capabilities, to guide project-specific consultation activity under the ESA, NMSA and MSFCMA towards longerterm mitigation designs to address noise sources that are identified as being dominant contributors to both accumulated acute and chronic noise in high-risk acoustic habitats. In addition, 'programmatic' NEPA evaluations and consultations are increasingly being performed by agencies with direct regulatory responsibility for noise-producing activities (Council on Environmental Quality 2014), often in partnership with NOAA. These actions seek to assess implications for populations, species, and places over regions and multi-regions and over multi-year time periods. Cooperative evaluation of environmental consequences, including noise consequences, of longerterm and wider-ranging activity is improving interagency information sharing and supporting the development of new tools to support risk assessment at these scales. Such tools would benefit from interagency cooperation to generate and contribute to registries of noisy events, particularly to improve information regarding actualized versus proposed activity profiles. Programmatic impact assessments and consultations also have the potential to improve characterization of noise budgets within acoustic habitats of management concern through longerterm monitoring requirements. 
Finally, improved characterizations of accumulated noisy activity would support NOAA's decisions regarding use of the agency's statutory authorities to strengthen localized protection for acoustic habitats. NOAA has applied its generalized authorities under the MMPA and ESA (Table 2) to regulate ship speeds in areas and during time periods when risks of collision with North Atlantic right whales are heightened. These regulations thus applied range-wide authorities to direct long-term, though more spatially restricted, mitigation in targeted areas. Monitoring required to support this action has in turn supported better understanding of collision risk, as well as measuring compliance and informing enforcement actions as necessary. Such generalized authorities are available to the agency within several statutes, and provide opportunity for establishing long-term mitigation (e.g. seasonal or year-round exclusion or reduction in noisy activity levels, use of quieter technology) in a high-risk acoustic habitat. Such actions must be supported by a needs analysis documenting the detrimental (although mostly sub-lethal) consequences of the noise source(s) that will be mitigated, on targeted NOAA-managed resource(s), included in the 'basis and purpose' of the rulemaking. In addition, NOAA's support for the development of Cetacean Biologically Important Areas has identified places, additional to those defined as critical for ESAlisted species, to inform management action across the many permitting and consultation actions currently being taken to address noise impacts on these species. Just as these areas will be modified in the future to reflect additional scientific information, their application to management actions should be evaluated over time to determine whether they are effective in enhancing the condition of the acoustic habitats they contain. Long-term monitoring within biologically important areas and critical habitats associated with highly vulnerable and acoustically sensitive cetacean populations (e.g. southern resident killer whales, North Atlantic right whales, Cook Inlet beluga whales) will be critical to establishing baselines for assessing success of multi-action mitigation, and determining whether existing or additional place-based management authorities are or would be effective.

\section{Realize the potential of National Marine Sanctuaries}

The activities discussed above seek to address wide-ranging, repeated, and long-term noise exposure by leveraging NOAA's species- and habitat- specific authorities to achieve noise reduction benefits within acoustic habitats where target species coexist with many other acoustically sensitive and active species. They also seek to interface with ecosystem-protection frameworks such as NOAA's Habitat Blueprint effort and the US NOP. National Marine Sanctuaries, however, represent key NOAA assets to achieve the ecological goals of acoustic habitat protection, due to their mandate to protect whole and functioning natural ecosystems (Table 2). Given the importance of sound to survivorship and well-being of diverse marine species and ecosystems, this ecosystem protection mandate extends to ecologically important environmental characteristics like sound and thus to the maintenance or restoration of viable acoustic habitats for a range of acoustically sensitive species that inhabit sanctuaries. Preserving, restoring, and maintaining natural acoustic habitats within sanctuaries is a complex endeavor, involving the development of new scientific capabilities, new management measures and processes, and outreach programs.

Currently, only 4 National Marine Sanctuaries (Stellwagen Bank, Olympic Coast, Cordell Bank, and Channel Islands) are operating long-term passive acoustic monitoring systems. Other sites do so periodically or are developing longer-term soundscape research programs in partnership with academic institutions. The Office of National Marine Sanctuaries is seeking to enhance these capabilities in collaboration with NOAA's Pacific Marine Environmental Laboratory, NOAA Fisheries, and the US National Park Service (NPS) through the development of the NOAA Noise Reference Station Network (NOAA Fisheries 2015b). The maturation of the Natural Sounds and Night Skies Division within the NPS has showcased the importance of developing systemwide, standardized, calibrated, and long-term noise measurement capability to support site-based but coordinated noise management objectives (Hatch \& Fristrup 2009). At Stellwagen Bank National Marine Sanctuary, where passive acoustic monitoring has more longevity, higher-resolution research focuses on characterizing acoustic variability among different habitat types, continuing to document speciesspecific acoustic behaviors, and identifying environmental signals of relevance to sanctuary species.

While management of acoustic habitats in protected areas, both terrestrial and aquatic, is relatively new to environmental protection activity, National Parks have been operating under defined soundscape management regulations for over a decade (NPS 2000, 2006). Key lessons have emerged that 
should be taken into account as National Marine Sanctuaries seek to digest acoustic habitat status and trend information in order to characterize effects and establish objectives for threat reduction. The development of metrics is a controversial step in environmental threat management. Both NOAA and NPS have learned that thresholds, in and of themselves, become short-hand for representing the agency's broader perspective for how noise influences wildlife. Thus, effect metrics should identify and communicate protection targets associated with acceptable levels of biological effect, rather than the levels of noise that are predicted to produce those effects. For example, parks have been successful in translating information regarding noise influence within their soundscapes into metrics of acceptable or unacceptable levels of communication interference, sleep disturbance and lost listening capability (NPS 2010). Such metrics are relatable to people (e.g. visitors and managers) as well as park wildlife, and synthesize impacts associated with many types of noise exposure (e.g. rare sudden loud events, accumulated disruptive noise events, and continuous background noise).

The National Park soundscape management experience further suggests that sites within a system may or may not share effect level targets for management. Variation among sites in effect reduction or maintenance objectives will be driven by a range of factors, including, but not limited to, the status of natural and human contributions to their soundscapes and prioritization of noise protection relative to other managed threats. However, long-term management action must reference site-specific estimates of pre-industrial levels as baselines for interpreting progress towards biologically relevant recovery. The reference condition for park soundscape management is clearly specified to be the historical, noise-free environment (NPS 2006, section 8.2.3). Sanctuary management should recognize the importance of measuring or estimating anthropogenic noise-free acoustic habitat conditions to calibrate incremental protective action both within sites as well as among sites.

Achieving noise management goals within National Marine Sanctuaries will require multi-faceted action. Some sources of distant propagating noise, as discussed above, will require international as well as other domestic activity. However, proposed activities that may (Stellwagen Bank) or are likely to (all other sanctuaries) result in injury to sanctuary resources are required to consult with NOAA (see Table 2). This requirement includes activities that are and are not prohibited from occurring within specific sanctu- aries, and it includes activities occurring outside sanctuary boundaries from which injury inside sanctuary boundaries may occur, as is often the case with noise. NMSA consultation results in recommendations to action agencies, not binding requirements; however, the recommendations carry liability associated with rejection, and they offer the potential for structured, long-term dialogue between NOAA and other federal agencies, as well as with the public, regarding acoustic habitat management goals and suggested mitigation to achieve those goals. Consultation authority can also incentivize stakeholders to invest in promising new mitigation techniques that could be used in proximity to sensitive or protected sites, including sanctuaries. The application of consultation authority to address noise impacts within sanctuaries is growing exponentially, but is currently limited by staff capacity. NOAA's overlapping authorities within sanctuaries provide additional opportunities to broaden the protective value of sanctuaries. Most sanctuaries protect resident or seasonal marine mammals, or endangered and threatened species, or commercial and recreationally important fish species and their essential habitat. In some cases, intra-agency consultations provide opportunities for NOAA to evaluate the noise implications of its own actions (e.g. issuance of Incidental Harassment Authorizations under the MMPA) on a sanctuary resource, providing opportunities for the agency to coordinate and strengthen its protective capabilities for specific species within these sites. Such opportunities are also increasingly being identified, but again are limited by staff capacity.

Finally, but perhaps most importantly, sanctuaries are a vital NOAA asset for building new constituencies to protect our coasts and oceans and for ensuring that people understand the role of sound and hearing to the healthy functioning of aquatic places. Sanctuaries, like parks, provide places for local conversations among people with different views about what is important to them about the current and future condition of their ocean. These conversations expose people to new scientific information regarding environmental effects as well as more nuanced perspectives on the practices of industries. Like air and water, the acoustic environment can be polluted and, in the 1970s, the US recognized noise as an environmental pollutant that necessitated regulation to protect human health (Noise Control Act 1972). But the protection of the holistic acoustic conditions that wildlife, and particularly animals that live underwater, need in order to survive and persist is only recently recognized as warranting international re- 
investment. Sanctuaries represent opportunities to educate current and future generations about the importance of natural acoustic habitats and what can be done to reduce the influence of noise on these habitats.

Acknowledgements. We thank all NOAA Ocean Noise Strategy participants for their contributions to ongoing discussions that informed this paper. Mimi D'Iorio (Marine Protected Area Center), Michael Thompson (Stellwagen Bank National Marine Sanctuary), Jesse Cleary (Duke University Marine Laboratory), and Michael Porter and Laurel Henderson (Heat, Light \& Sound Research, Inc.) contributed to figures and tables presented in this paper.

\section{LITERATURE CITED}

Anadromous Fish Conservation Act (AFCA) (1965) Public Law 89-304, 79 Stat. 1125, 16 USC 757a-757g, as amended by Public Law 89-304. http://legcounsel.house. gov/Comps/Anadromous \% 20Fish\% 20Conservation $\% 20$ Act.pdf

Andrew RK, Howe BM, Mercer JA (2002) Ocean ambient sound: comparing the 1960s with the 1990s for a receiver off the California coast. Acoust Res Lett Online 3:65-70

Barber JR, Crooks KR, Fristrup KM (2010) The costs of chronic noise exposure for terrestrial organisms. Trends Ecol Evol 25:180-189

Charif RA, Clapham PJ, Clark CW (2001) Acoustic detections of singing humpback whales in deep waters off the British Isles. Mar Mamm Sci 17:751-768

Clark CW, Ellison WT, Southall BL, Hatch L, Van Parijs SM, Frankel A, Ponirakis D (2009) Acoustic masking in marine ecosystems: intuitions, analysis, and implication. Mar Ecol Prog Ser 395:201-222

Coastal Zone Management Act (CZMA) (1972) Public Law No. 92-583, 86 Stat. 1280, enacted October 27, 1972, 16 U.S.C. $\S \S 1451-1464$, Chapter 33. https://coast.noaa. gov/czm/media/CZMA_10_11_06.pdf

Coral Reef Conservation Act (CRCA) (2000) Public Law 106-562; 16 U.S.C. 6401 et seq. www.coris.noaa.gov/ activities/actionstrategy/08_cons_act.pdf

Council on Environmental Quality (2014) Final guidance for effective use of programmatic NEPA reviews. https:// www.whitehouse.gov/sites/default/files/docs/effective use_of_programmatic_nepa_reviews_final_dec2014_ searchable.pdf (accessed 24 June 2015)

Endangered Species Act (ESA) (1973) Public Law 93-205, 87 Stat. 884, codified as amended at 16 U.S.C. $\S$ ch. 35 $\S 1531$ et seq. https://www.gpo.gov/fdsys/pkg/USCODE2012-title16/html/USCODE-2012-title16-chap35sec1531.htm

Erbe C, Williams R, Sandilands D, Ashe E (2014) Identifying modeled ship noise hotspots for marine mammals of Canada's Pacific region. PLoS ONE 9:e89820

European Union Marine Strategy Framework Directive (EUMSFD) (2008) Directive 2008/56/EC of the European Parliament and of the Council of 17 June 2008 establishing a framework for community action in the field of marine environmental policy (Marine Strategy Framework Directive). http://eur-lex.europa.eu/legal-content/ EN/TXT/?uri=CELEX:32008L0056
Executive Order 13158 (2000) Executive Order 13158 of 26 May 2000. Marine Protected Areas. Fed Reg 65:3490934911. Available at www.gpo.gov/fdsys/pkg/FR-200005-31/pdf/00-13830.pdf (accessed 24 June 2015)

Executive Order 13547 (2010) Executive Order 13547 of 19 July 2010. Stewardship of the Ocean, Our Coasts, and the Great Lakes. Fed Reg 75:43023-43027. Available at www.whitehouse.gov/the-press-office/executive-orderstewardship-ocean-our-coasts-and-great-lakes (accessed 24 June 2015)

Federal Power Act (FPA) (1920) 16 U.S.C. 791-828c; Chapter 285, 41 Stat. 1063, as amended through Public Law 11494. http://legcounsel.house.gov/Comps/Federal\%20Power \%20Act.pdf

Fish and Wildlife Coordination Act (FWCA) (1934) 16 U.S.C. 661-667e, Chapter 55, 48 Stat. 401, as amended through Public Law 89-72. https://www.usbr.gov/power/ legislation/fwca.pdf

Food and Agriculture Organization of the United Nations (2015) Productivity susceptibility assessments. Available at www.fao.org/fishery/eaf-net/eaftool/eaf_tool_55 (accessed 24 June 2015)

- Francis CD, Barber JR (2013) A framework for understanding noise impacts on wildlife: an urgent conservation priority. Front Ecol Environ 11:305-313

Goldbogen JA, Southall BL, DeRuiter SL, Calambokidis J and others (2013) Blue whales respond to simulated mid-frequency military sonar. Proc R Soc B 280: 20131657

> Hatch LT, Fristrup KM (2009) No barrier at the boundaries: implementing regional frameworks for noise management in protected natural areas. Mar Ecol Prog Ser 395: 223-244

Hatch LT, Clark CW, Van Parijs SM, Frankel AS, Ponirakis DW (2012) Quantifying loss of acoustic communication space for right whales in and around a US national marine sanctuary. Conserv Biol 26:983-994

> Holt MM, Noren DP, Veirs V, Emmons CK, Veirs S (2009) Speaking up: killer whales (Orcinus orca) increase their call amplitude in response to vessel noise. J Acoust Soc Am 125:EL27-EL32

International Maritime Organization (2014) Marine Environmental Protection Committee Annex: guidelines for the reduction of underwater noise from commercial shipping. MEPC Circular 66/17. IMO, London

Janik VM, Slater PJB (1998) Context-specific use suggests that bottlenose dolphin signature whistles are cohesion calls. Anim Behav 56:829-838

Ladich F (ed) (2015) Sound communication in fishes. Animal signals and communication, Vol 4. Springer-Verlag, Vienna

Lillis A, Eggleston DB, Bohnenstiehl DR (2014) Estuarine soundscapes: distinct acoustic characteristics of oyster reefs compared to soft-bottom habitats. Mar Ecol Prog Ser 505:1-17

Magnuson-Stevens Fishery Conservation and Management Act (MSFCMA) (1996) Public Law 94-265, 90 Stat. 331, codified as amended at 16 U.S.C. $\S \S 1801-1884$. www. fisheries.noaa.gov/sfa/laws_policies/msa/documents/msa _amended_2007.pdf

Marine Mammal Protection Act (MMPA)(1972) Public Law 92-522, 86 Stat. 1027, codified as amended at 16 U.S.C. $\S \S 1361-1423 \mathrm{~h}$. www.nmfs.noaa.gov/pr/pdfs/laws/mmpa .pdf

McCarthy E (2004) International regulation of underwater 
sound: establishing rules and standards to address ocean noise pollution. Kluwer Academic Publishers, Boston, MA

McDonald MA, Hildebrand JA, Wiggins SM (2006) Increases in deep ocean ambient noise in the Northeast Pacific west of San Nicolas Island, California. J Acoust Soc Am 120:711-718

McWilliam JN, Hawkins AD (2013) A comparison of inshore marine soundscapes. J Exp Mar Biol Ecol 446:166-176

Mennitt D, Sherrill K, Fristrup K (2014) A geospatial model of ambient sound pressure levels in the contiguous United States. J Acoust Soc Am 135:2746-2764

Merchant ND, Fristrup KM, Johnson MP, Tyack PL, Witt MJ, Blondel P, Parks SE (2015) Measuring acoustic habitats. Methods Ecol Evol 6:257-265

Moore SE, Randall RR, Southall BL, Ragen TJ, Suydam RS, Clark CW (2012a) A new framework for assessing the effects of anthropogenic sound on marine mammals in a rapidly changing Arctic. BioScience 62:289-295

Moore SE, Stafford KM, Humfrey M, Berchok C and others (2012b) Comparing marine mammal acoustic habitats in Atlantic and Pacific sectors of the High Arctic: year-long records from Fram Strait and the Chukchi Plateau. Polar Biol 35:475-480

Morano JL, Salisbury DP, Rice AN, Conklin KL, Falk KL, Clark CW (2012) Seasonal and geographical patterns of fin whale song in the western North Atlantic Ocean. J Acoust Soc Am 132:1207-1212

Myrberg AA Jr (1981) Sound communication and interception in fishes. In: Tavolga WN, Popper AN, Fay RR (eds) Hearing and sound communication in fishes. SpringerVerlag, New York, NY, p 345-425

National Environmental Policy Act (NEPA) (1969) Public Law 91-190, 42 U.S.C. 4321-4347, as amended by Public Law 94-52, Public Law 94-83, and Public Law 97-258, § 4(b). https://ceq.doe.gov/laws_and_executive_orders/the _nepa_statute.html

National Marine Protected Areas Center (2011) Definition and classification system for US Marine Protected Areas. http://marineprotectedareas.noaa.gov/pdf/helpfulresources/factsheets/mpa_classification_may2011.pdf (accessed 24 June 2015)

National Marine Sanctuaries Act (NMSA) (1992) Title 16, Chapter 32, Sections 1431 et seq USC as amended by Pub L 106-513. http://sanctuaries.noaa.gov/library/national/ nmsa.pdf

National Ocean Council (2013a) National Ocean Policy Implementation Plan. https://www.whitehouse.gov/sites/ default/files/national_ocean_policy_implementation_ plan.pdf (accessed 24 June 2015)

National Ocean Council (2013b) Marine planning handbook. https://www.whitehouse.gov/sites/default/files/ final_marine_planning_handbook.pdf (accessed 24 June 2015)

National Park Service (2000) Director's Order \#47: soundscape preservation and noise management. www.nps. gov/policy/DOrders/DOrder47.html (accessed 24 June 2015)

National Park Service (2006) Management policies. www.nps. gov/policy/mp/Index2006.htm (accessed 24 June 2015)

National Park Service (2010) Zion National Park Soundscape Management Plan. US Department of the Interior, Washington, DC

National Research Council of the US National Academies (2003) Ocean noise and marine mammals. National
Academy Press, Washington, DC

NOAA (National Oceanic and Atmospheric Administration) Fisheries (2015a) Habitat Blueprint Focal Areas. www. habitat.noaa.gov/habitatblueprint (accessed 24 June 2015)

NOAA Fisheries (2015b) Sound check: new NOAA effort underway to monitor underwater sound. www.st.nmfs. noaa.gov/feature-news/acoustics (accessed 24 June 2015)

Noise Control Act (NCA) (1972) 42 U.S.C. $\$ 4901$ et seq. www.gsa.gov/graphics/pbs/Noise_Control_Act_of_1972. pdf

Normandeau Associates (2012) Effects of noise on fish, fisheries, and invertebrates in the US Atlantic and Arctic from energy industry sound-generating activities. A Workshop Report for the US Dept of the Interior, Bureau of Ocean Energy Management, Herndon, VA

Northeast Regional Planning Body (2015) Northeast Regional Planning Body draft work plan for deliberation June 3-4, 2015. Available at http://neoceanplanning.org/ wp-content/uploads/2015/06/RPB-Work-Plan-DecisionJune-2015.pdf (accessed 24 June 2015)

Oil Pollution Act (OPA) (1990) Public Law 101-380, 33 U.S.C. ch $40 § 2701$. https://www.gpo.gov/fdsys/pkg/ STATUTE-104/pdf/STATUTE-104-Pg484.pdf

Oleson EM, Širovi A, Bayless AR, Hildebrand JA (2014) Synchronous seasonal change in fin whale song in the North Pacific. PLoS ONE 9:e115678

Parks SE, Johnson M, Nowachek D, Tyack PL (2010) Individual right whales call louder in increased environmental noise. Biol Lett 7:33-35

> Parks SE, Miksis-Olds JL, Denes SL (2014) Assessing marine ecosystem acoustic diversity across ocean basins. Ecol Inform 21:81-88

> Payne R, Webb D (1971) Orientation by means of long-range acoustic signaling in baleen whales. Ann NY Acad Sci 188:110-141

Pijanowski BC, Villanueva-Rivera LJ, Dumyahn SL, Farina A and others (2011) Soundscape ecology: the science of sound in the landscape. BioScience 61:203-216

> Purser J, Radford AN (2011) Acoustic noise induces attention shifts and reduces foraging performance in threespined sticklebacks (Gasterosteus aculeatus). PLoS ONE 6:e17478

> Radford AN, Kerridge E, Simpson SD (2014) Acoustic communication in a noisy world: Can fish compete with anthropogenic noise? Behav Ecol 25:1022-1030

Rountree RA, Gilmore RG, Goudey CA, Hawkins AD, Luczkovich J, Mann D (2006) Listening to fish: applications of passive acoustics to fisheries science. Fisheries 31: 433-446

Simpson SD, Purser J, Radford AN (2015) Anthropogenic noise compromises antipredator behavior in European eels. Glob Change Biol 21:586-593

Slabbekoorn H, Bouton N, van Opzeeland I, Coers A, ten Cate C, Popper AN (2010) A noisy spring: the impact of globally rising underwater sound levels on fish. Trends Ecol Evol 25:419-427

SMRU Consulting (2015) Population consequences of disturbance. www.smruconsulting.com/locations/europe/ pcod/ (accessed 24 June 2015)

Southall B, Berkson J, Bowen D, Brake R and others (2009) Addressing the effects of human-generated sound on marine life: an integrated research plan for US federal agencies. Interagency Task Force on Anthropogenic 
Sound and the Marine Environment of the Joint Subcommittee on Ocean Science and Technology, Washington, DC

Staaterman E, Rice AN, Mann DA, Paris CB (2013) Soundscapes from a tropical eastern Pacific reef and a Caribbean Sea reef. Coral Reefs 32:553-557

Tyack PL, Clark CW (2000) Communication and acoustic behavior of dolphins and whales. In: Au WWL, Popper AN, Fay FF (eds) Springer handbook of auditory research Vol 12: hearing by whales and dolphins. Springer, New York, NY, p 156-224

Urick RJ (1983) Principles of underwater sound. McGrawHill, New York, NY

Van Parijs SM, Curtice C, Ferguson MC (eds) (2015a) Biologically Important Areas for cetaceans within US

Editorial responsibility: Brandon L. Southall (Guest Editor), Santa Cruz, California, USA waters. Aquat Mamm 41(Spec Issue):1-128

- Van Parijs SM, Baumgartner M, Cholewiak D, Davis G and others (2015b) NEPAN: a US northeast passive acoustic sensing network for monitoring, reducing threats and the conservation of marine animals. Mar Technol Soc J 49: 70-86

> Versluis M, Schmitz B, von der Heydt A, Lohse D (2000) How snapping shrimp snap: through cavitating bubbles. Science 289:2114-2117

Voellmy IK, Purser J, Simpson SD, Radford AN (2014) Increased noise levels have different impacts on the antipredator behaviour of two sympatric fish species. PLoS ONE 9:e102946

Wenz GM (1962) Acoustic ambient noise in the ocean: spectra and sources. J Acoust Soc Am 34:1936-1956

Submitted: June 29, 2015; Accepted: January 4, 2016

Proofs received from author(s): April 24, 2016 